\title{
Researching Intercultural Learning: Investigations in Language and Education
}

\section{Lixian Jin and Martin Cortazzi (Editors)}

New York: Palgrave Macmillan, 2013, 287 pages.

This wide-ranging collection edited by two scholars well known for their work in the field of intercultural contact and communication comprises 13 chapters presenting research carried out primarily in relation to the United States, the United Kingdom, Denmark, Germany, France, Hong Kong, Mainland China, and New Zealand. The book is structured into three sections: Researching Transformations of Cultures of Learning through Internationalization; Intercultural Learning in Developing Language and Academic Skills; and Transcultural Adjustment and Bridging Distances. However, the editors note that all chapters are concerned with three overlapping and mutually complementary levels of cultural analysis: a level of analysis the goal of which is "to promote awareness and knowledge of ... other cultures and to be able to function within them" (p. 3); a "more complex level" that "moves from descriptive to interpretive and critical perspectives" (p. 4) by means of real-life communication in an additional language; and a "more reflexive level" at which "learning about culture-or possibly any other learning-is itself a cultural enterprise in a cultural context which includes the cultural orientations and practices of those learning and of those learned about" (p. 5).

As a resource text for anyone interested in the educational and linguistic dimensions of intercultural contact and communication, the collection has a number of merits. The inclusion of studies with not only a Western but also an Asian focus is valuable, and the recurrent emphasis on the theme of cultural learning through various forms of communication (e.g., academic writing, immersion, classroom interaction, tutorials, and electronic communication) provides opportunities to explore particular themes in varied contexts. For example, the demands of understanding and mastering academic writing in English are examined through the experience of international students in the US (chapter 1), of non-traditional (i.e., mature) candidates undertaking university study in the UK (chapter 7), and of Chinese students in New Zealand (chapter 8). Similarly, the theme of varying teacher-student and student-student relationships/communication, with potentially meaningful consequences for both home and visiting participants, is studied at the primary school level in Hong Kong (chapter 4), in Mainland China (chapter 5), and in a number of varied higher education settings such as with international students and their teachers in the UK reflecting on their diverse perceptions of educational practices (chapter 2), with Japanese students taking part in tutorials in the UK (chapter 6), or with Hong Kong students engaging in onesemester exchange visits to a variety of universities abroad (chapter 12). 
Predictably, English plays a significant role as a medium of international communication in many of the chapters in this text, and if any criticism were to be offered, it might point in the direction of a need for greater attention to other languages and related cultural patterns. In response, however, it is important to recognize that the collection does offer enlightening insights into the teaching of German in various Eastern European and Asian (mainly Chinese) university contexts (chapter 9), the use of French by international university students in that country (chapter 10), and the learning of Mandarin Chinese by Anglophone university students (chapter 11). Moreover, one of the most interesting studies in the book (chapter 3) presents a fascinating analysis of the multiple educational heritages in Denmark, where a more lecture-style (German) and a more interactional (Danish) tradition coexist and to some extent compete: university students' responses to this complexity interestingly reveal a general tendency for Danish participants to prefer the more unidirectional, lecture-focused model, whereas international students either from Europe or Asia often favor the admixture of a more egalitarian, group-discussion element. Above all, as the authors note, the richness of such intercultural debate can in a broader sense help us "begin to understand the origin of commonly and firmly held pedagogical beliefs and also see and understand trends which go against those values" (p. 73).

In all, Researching Intercultural Learning: Investigations in Language and Education should appeal to readers of the TESL Canada Journal who are interested in the experience of diverse learners in Canadian programs (and the illuminating opportunities for their mainstream counterparts too), in variations on intercultural patterns of discourse both in and outside the classroom, or in resources to assist themselves or their students when preparing for intercultural endeavors at home or abroad.

John Sivell

\section{The Reviewer}

John Sivell is a professor in the Department of Applied Linguistics and Interim Director of the Centre for Intercultural Studies at Brock University, St. Catharines, ON. 